\title{
La Contabilidad y sus orígenes, caso ciudad de Pilar - Paraguay
}

\section{Laura Isabel Ozuna}

Universidad Nacional de Pilar

$\underline{\text { lau.ozu@gmail.com }}$

\section{RESUMEN}

Diversos autores han abordado el origen de la Contabilidad tanto desde la óptica de su evolución histórica como a través de la evolución del pensamiento contable según diferentes paradigmas. Este trabajo pretende realizar una aproximación teórica a los orígenes históricos que ha tenido esta profesión en la ciudad de Pilar, Departamento de Ñeembucú - Paraguay, hasta su consolidación como carrera de grado en la Universidad Nacional de Pilar. La metodología del trabajo es de revisión bibliográfica y concluye con la presentación de la estructura actual del plan curricular de formación del profesional contador en la Universidad Nacional de Pilar.

Palabras clave: Contabilidad; historia; Universidad Nacional de Pilar 


\title{
Accounting and its origins, the case of the city of Pilar - Paraguay
}

\begin{abstract}
Several authors have addressed the origin of accounting both from the perspective of its historical evolution and through the evolution of accounting thinking according to different paradigms. This work aims to make a theoretical approach to the historical origins that this profession has had in the Pilar city, Neembucú Department - Paraguay, until its consolidation as a degree career at the Universidad Nacional de Pilar. The work methodology is a literature review and concludes with the presentation of the current structure of the curriculum for training professional accountants at the Universidad Nacional de Pilar.
\end{abstract}

Key words: Accounting; history; Universidad Nacional de Pilar

Artículo recibido: 27 marzo 2021 Aceptado para publicación: 30 abril 2021

Correspondencia: lau.ozu@gmail.com Conflictos de Interés: Ninguna que declarar 


\section{INTRODUCCIÓN}

En el presente trabajo de revisión bibliográfica se tiene como objetivos, conocer los orígenes de la Contabilidad y describir la estructura del plan curricular de formación del profesional contador en la Universidad Nacional de Pilar.

Para iniciar, cabe mencionar que los orígenes de la contabilidad, son tan remotos como la civilización misma, por tanto, la fecha en que se origina no es posible determinarla con precisión. Gertz (1996) citado por Moran (2007) señala que hacia el año 6000 a.C., ya existían elementos para el desarrollo de la actividad contable, tales como la escritura y los números, el concepto de propiedad, operaciones comerciales, además es posible que ya hayan existido formas rudimentarias de crédito en los mercados. Los antecedentes llegan hasta Fray Luca Pacioli y los Estudios Mercantiles y las Escuelas de Comercio de España, que, a principios del siglo XX, representó la actual Facultad de Ciencias Económicas y Empresariales del campus de Vegazana. Se observó además que la actividad contable tiene permanentemente relación con los valores morales e intelectuales de la época (Moran, 2007).

Mileti y otros (2001) abordaron el fenómeno del avance de la contabilidad desde dos ópticas, una de ellas a través de la evolución histórica de la disciplina contable, de modo a determinar cuál es el período en que aparece la necesidad de regulación; la otra, por la evolución de los paradigmas del pensamiento contable, a fin de identificar en qué corriente se circunscribe y si fue objeto de investigaciones. Con esto intentaron establecer si el fenómeno regulador de la disciplina posee un marco teórico que respalde su emisión, por tanto, requiere estudiar la relación existente entre la teoría de la contabilidad y las normas contables.

Por su parte Montesinos Julve (1997) citado por Mileti y otros (2001, p. 329) consideró cuatro grandes períodos en el desarrollo de la Contabilidad:

1) un período empírico: comprende desde la Antigüedad y la Alta Edad Media hasta 1202, fecha del "Liber Abaci” de Leonardo Fibonacci de Pisa.

2) período de génesis y aparición de la Partida Doble: que se inicia con la revitalización del comercio como consecuencia de las Cruzadas, en el siglo XIII y se extiende hasta la publicación de la obra de Pacioli en 1494. 
3) período de expansión y consolidación de la Partida Doble, en el que no hay avances técnicos ni científicos de importancia que se extiende hasta la primera mitad del siglo XIX

4) período científico que comienza en el siglo XIX y se extiende hasta nuestros días

La profesión de contador surge debido a que antiguamente los grandes señores se hacían acompañar de hombres de confianza cuando trataban operaciones comerciales de importancia, préstamos, financiamientos, etc

Al hablar de Contabilidad y sus orígenes, merece una especial mención Fray Luca Bartolomeo Pacioli, monje franciscano, de origen italiano, conocido por sus destrezas matemáticas, quien en el año 1494 publicó el libro Summa Arthmética, Geometría, Proportioni, e Proportionalita. Una de las secciones de este libro, denominado Particularis de Computis et Scripturis, se constituyó en un tratado de contabilidad, donde se sentaron los principios de la Partida Doble, conocida también como Método Veneciano, pues éste venía siendo utilizado por los comerciantes de Venecia. Esta obra le valió a Pacioli ser considerado como el Padre de la Contabilidad (Cano, Restrepo y Villa, 2017) (Moran, 2007).

Quinche (2006) señaló que la historia de la contabilidad es un campo poco estudiado dentro de la disciplina en Latinoamérica, lo cual debe fomentarse en la academia, ya que el conocimiento de los antecedentes históricos puede ser útil en la toma de decisiones; además, conocer el contexto, simbologías, instituciones y necesidades sociales y económicas, permiten comprender la relación de la contabilidad con el contexto, e identificar la pertinencia de las prácticas desarrolladas en la misma como también, establecer regulaciones requeridas en la contabilidad nacional.

Casal y Viloria (2007) reflexionaron sobre el contexto en que se desarrolla la ciencia contable, y proponen como punto de partida para su reflexión y reconstrucción, a la investigación, de modo a que la disciplina internalice los cambios del entorno y las universidades la adopten como una ciencia transdisciplinaria, dinámica e interpretativa.

En Colombia, la educación en el ámbito contable tuvo un desarrollo lento. En la primera mitad del siglo XX estaba regulada por normas legales, y los cambios en la estructura educativa de los diversos niveles apuntaban a aspectos de forma, mientras que los cambios de fondo no respondían a necesidades reales, más bien se encontraban dispersos, y primaba el interés por el control social, antes que la formación de un profesional 
contable competente. La consolidación de la formación del profesional contable pasó por períodos de adaptación, resistencia y evolución constante (Arévalo, 2015).

En Argentina, se observó una evolución de la profesión contable relacionada con los estudios de contabilidad y éstos a su vez, desarrollados según los modelos económicos que el país iba adoptando, aumentando su complejidad, llegando a un período de agilización de la profesión al igual que las regulaciones, en los primeros años del siglo XX. Tras varios cambios, en 1945 se logra la unificación de la legislación, y a partir de 1973 se consolidó la figura profesional (Carrizo, 2015).

En cuanto a Paraguay, antecedentes sobre los orígenes de la profesión contable se remontan a la época de la Colonia, con la expedición de don Pedro de Mendoza. La misma zarpó con destino al Río de la Plata en 1535, y con ella arribaron al país varios profesionales, entre ellos el Contador Juan de Cáceres. En aquella época el cargo, era parte de la Real Hacienda. Otro nombramiento realizado para el cargo fue hecho por el adelantado Ortiz de Zárate, en 1575 (Colegio de Contadores del Paraguay, 2016). Posteriormente encontramos a las Escuelas de Comercio, que fueron formadoras de profesionales denominados Contadores Públicos y Peritos Mercantiles (Rojas, 2010).

El desarrollo de la contabilidad en el Paraguay no está exenta a los cambios y evoluciones del contexto económico internacional, pues en materia de legislación tributaria se han dado varios cambios. En el 1991, con la Ley 125 “Que establece el nuevo régimen tributario", en 2004, la ley 2421 "De Reordenamiento administrativo y adecuación fiscal", y en el año 2019 con la Ley 6380 "De Modernización y simplificación tributaria", con el propósito de adecuar las normas tributarias al contexto globalizado y de fiscalidad internacional. Es importante mencionar que previo a la ley 125, ya existían en el país normativas diversas que hacían al aspecto tributario, pero con la misma, se unificaron en un mismo cuerpo legal.

\section{METODOLOGÍA}

El objetivo de este trabajo es realizar un recuento histórico resumido sobre el desarrollo de la disciplina contable en el contexto internacional, para luego centrarse en la formación académica del profesional contable en la ciudad de Pilar, República del Paraguay, desde su aparición como oficio hasta su consolidación como carrera de grado. Se desarrolló mediante revisión bibliográfica recurriendo a bases de datos de revistas académicas y 
documentos de la Facultad de Ciencias Contables, Administrativas y Económicas de la Universidad Nacional de Pilar, a los que se tuvo acceso en el contexto de la investigación.

\section{RESULTADOS Y DISCUSIÓN}

\section{La profesión de Contador en el Paraguay}

La aparición de los primeros contadores y la institución de Contadores en el Paraguay, se observó con la expedición de don Pedro de Mendoza, que partió hacia el Río de la Plata y estuvo acompañada de diversos profesionales, tiempo en el cual uno de los cargos de la Real Hacienda era el de Contador. En 1534 está fechado el título de Contador para Juan de Cáceres. Posteriormente, en 1575, el adelantado Ortiz de Zárate realizó el nombramiento de Contador a favor de Gerónimo Ochoa de Eizaguirre. A partir de allí fueron varios quienes se han ocupado de llevar un registro de las cuentas reales hasta el siglo XIX. El libro de contabilidad más antiguo de la Sección Histórica del Archivo Nacional de Asunción data de 1569 (Colegio de Contadores del Paraguay, 2016).

El gobierno provisorio establecido en la etapa final de la Guerra contra la Triple Alianza (1864-1870), dictó un decreto de fecha el 18 de noviembre de 1869, que se transcribe:

"Considerando la utilidad y conveniencia para el país, la creación de contadores y balanceadores públicos, como uno de los elementos que más auxilian al comercio y demás ramos de interés público, ha acordado y Decreta:

Art. $1^{\circ}$ : Queda instruida en la República la profesión de contador y balanceador público, cuyo ejercicio es libre, sin más requisito que el de la idoneidad.

Art. $2^{\circ}$ : Deberá sujetarse en su ejercicio a las leyes, sobre contadores y a las de los escribanos en lo que fueren compatibles.

Art. $3^{\circ}$ : El individuo que pretendiere ejercer la profesión de contador y balanceador público, ocurrirá al Tribunal Superior de Justicia para obtener el diploma, previo los exámenes y demás requisitos.

Art. $4^{\circ}$ : Publíquese y dése al Registro Nacional. Cirilo A. Rivarola, Carlos Loizaga, José Díaz de Bedoya".

A partir de este decreto, varias personas se han presentado ante los tribunales dedicándose a la contabilidad y balanceo público. Se destaca la labor de Jorge López Moreira, de nacionalidad brasileña que llegó al país como funcionario administrativo del ejército brasileño, durante la Guerra contra la Triple Alianza (1864-1870). El mismo se dedicó a 
difundir los servicios contables y a la enseñanza; fue contador de importantes firmas comerciales e industriales del país (Colegio de contadores del Paraguay, 2016).

López Moreira, además de trabajar como contador, se dedicaba a la enseñanza; también lo hacía el napolitano Leopoldo Gómez de Terán, “quien fue contratado como docente del Colegio Nacional de la Capital; dictaba clases de Teneduría de Libros por la noche, en forma particular, en su residencia" (Colegio de Contadores del Paraguay, 2016, p. 9)

\section{EI Instituto Paraguayo y la Escuela de Comercio}

El Instituto Paraguayo fue fundado en 1895 y estableció su sección comercial a cargo de Jorge López Moreira. A iniciativa de Juan Z. Campos y del Centro de Empleados de Comercio, se fundó en 1906 la Escuela de Comercio, que se constituyó como Centro de Contabilidad, para proporcionar formación profesional a los socios de esa entidad gremial. El número de alumnos no superaba 25 , y la enseñanza era gratuita. Sus primeros profesores fueron Jorge López Moreira, quien a la vez desempeñaba el cargo de director, y Manuel Irala. La administración estaba a cargo de Alfonso B. Campos, quien a su vez se desempeñaba como secretario del Centro de Empleados de Comercio (Colegio de Contadores del Paraguay, 2016) (Rojas, 2010).

En 1913, en reemplazo de Jorge López Moreira asumió como director, el paraguayo Alfonso B. Campos, y desde 1914 se estableció un nuevo Plan de Estudios, actualizado a la enseñanza comercial de la época. Además de la carrera de Contador Público, también se impartían clases para Traductor Público y Perito Caligráfico (Colegio de Contadores del Paraguay, 2016) ya que pronto superó sus objetivos iniciales. La Escuela de Comercio se denominó “Jorge López Moreira” en homenaje a su fundador (Rojas, 2010).

La Escuela de Comercio, desde sus inicios contó con apoyo oficial y le era permitido utilizar las instalaciones del Colegio Nacional, fue nacionalizada poco antes de la guerra del Chaco. El número de Escuelas de comercio creció a medida que transcurría el tiempo, y en su mayoría, eran de gestión privada. (Rojas, 2010)

"Se destaca el aporte de la destacada feminista paraguaya y primera mujer en obtener un grado universitario, Serafina Dávalos, creó la Escuela Mercantil de Niñas, en 1904, con el objeto de formar contadoras y peritas mercantiles" (Colegio de Contadores, 2016, p. 10).

Desde ese entonces, la instrucción pública ha ido en paulatino crecimiento, dándose paso las escuelas normales, de las que iban egresando docentes capacitados; también las 
escuelas superiores de las cabeceras de distritos, las medias y las elementales de barrios y compañías rurales se encargaban de la instrucción primaria de la niñez (Rojas, 2010).

\section{Antecedentes legales}

La presente investigación permitió acceder a un documento, aprobado por el Congreso Legislativo en fecha 18 de junio de 1902 y promulgado el 21 de junio de mil novecientos dos, donde se menciona que fue publicado en la Gaceta Oficial $N^{\circ} 1$ del año 1902. Este documento, en su artículo primero, autorizó al Instituto Paraguayo a expedir títulos de Perito Mercantil, Contador Público y Dependientes o Empleados de Comercio, de acuerdo con el plan de estudios y sus programas de enseñanza, así como su reglamentación que tuvieren la aprobación del Consejo S. y Superior. El artículo segundo de este documento señala que los alumnos que hayan probado todos los cursos contenidos en el Plan de Estudios, obtendrán títulos de Perito Mercantil y Contador Público; los que hayan probado los dos primeros cursos, los de Empleados o Dependientes de Comercio; .... Se aclara que el término "probado" aparece en el documento (Corte Suprema de Justicia , 2019)

Por Ley 1135 del año 1930 se reglamenta el ejercicio de la profesión de peritos mercantiles o contadores públicos. Esta ley establece que los cargos de la Administración Pública en que sean indispensables conocimientos técnicos de contabilidad serán desempeñados por peritos mercantiles. Sigue diciendo el referido documento:

Se requiere la intervención de los profesionales matriculados de conformidad con las disposiciones pertinentes de la Ley Orgánica de los Tribunales en los siguientes asuntos cuando

revistan carácter

judicial:

a) Informes, balances, inventarios, compulsas de libros, cuentas y documentos comerciales;

b) Partición de herencias, no habiendo conformidad entre las partes;

c) Liquidación de Sociedades;

d) Concurso civil de acreedores, procedimiento de convocación de acreedores y quiebras.

Los jueces o tribunales no darán curso a los instrumentos mencionados más arriba, que no lleven firma de tales profesionales (Poder Legislativo, 1930).

\section{La educación contable en Paraguay}

La educación en el Paraguay atravesó varias reformas en los años 1904, 1924, 1931 y 1956 (Ministerio de Educación y Ciencias , 2019) 
En el marco de una serie de reformas de la educación en el Paraguay se incluyó un programa de formación profesional en instituciones de Enseñanza Comercial. La misma inició en el año 1925, y fue establecido por Decreto $\mathrm{N}^{\circ}$ 21.354, donde "se establecen tres niveles, la enseñanza media (para auxiliares de escritorio), la profesional (para Tenedores de Libros) y la superior (para Peritos Mercantiles)" (Organización de los Estados Interamericanos para la Educación).

En una etapa posterior, con la reforma del Plan de estudios establecida por Decreto 5515 del año 1941, se dispuso que la Enseñanza Comercial tendría una duración de seis años, y culminaría con el título de Contador Público. El objetivo, que los Contadores egresados fueran capaces de integrarse a las actividades mercantiles en todas sus instancias.

Posteriormente, la estructura adaptó la enseñanza comercial al sistema de la educación media. En el mismo, posterior al ciclo básico de formación, se estableció un período de estudios de 3 años y se otorgaba el título de Bachiller Comercial, donde se han tenido en cuenta las condiciones siguientes, según informe de la Organización de los Estados Interamericanos (p. 10):

- Los técnicos medios que puedan trabajar como auxiliares de escritorio, cuentacorrentista de bancos, cajeros, despachantes de aduanas y tareas afines.

- Los Contadores Públicos orientados a la contabilidad, el peritaje y la auditoría; éstos constituyen técnicos de nivel superior. En esta etapa la formación de los técnicos medios está asignada a la enseñanza media y los técnicos de nivel superior a la enseñanza universitaria.

El plan de estudios de la enseñanza del Bachillerato Comercial se estableció por Decreto 27295 de fecha 5 de marzo de 1963, posteriormente, en las innovaciones educacionales del año 1973 se propusieron ajustes para la enseñanza comercial dentro del esquema del Bachillerato Técnico Diversificado. A partir del año 1974 la modalidad del Bachillerato Comercial se regía por Resolución 832/74. En la misma se determinaban las modalidades de pruebas de evaluación, que abarcan períodos cuatrimestrales y exámenes finales, de regularización y complementarios (Organización de los Estados Interamericanos para la Educación).

En la ciudad de Pilar, funcionó la Escuela Nacional de Comercio hasta el año 1985, cuando por resolución ministerial $N^{\circ} 2028$, se crea el Centro Regional de Educación Mariscal Francisco Solano López (Rivero Brest, 2012). 


\section{Formación universitaria del Contador Público}

La Universidad Nacional de Asunción, creada en el año 1889, es la pionera en el país en la formación de profesionales con nivel de grado. La actual carrera de Contaduría Pública, depende de la Facultad de Ciencias Económicas. Por Resolución del 5 de junio de 1931, el Consejo Superior Universitario crea la Escuela Libre de Ciencias Económicas y Políticas, dependiente de la Facultad de Derecho y Ciencias Sociales. Ésta inicialmente funcionó bajo la dependencia de la Facultad de Derecho en carácter de Instituto, pero era dirigida administrativamente por un Consejo constituido por los contadores fundadores. Las personas que aprobaban los exámenes optaban al diploma de Perito Financiero. El programa de estudios contenía temas económicos, agrarios y administrativos, estadística, demografía, estudios bancarios y financieros, y lenguas europeas. El 21 de enero de 1937 se creó de manera definitiva, la Facultad de Ciencias Económicas, por Decreto 9936 del Poder Ejecutivo (Facultad de Ciencias Económicas - Universidad Nacional de Asunción, 2019).

\section{El Contador en la Universidad Nacional de Pilar}

El 14 de julio de 1991, en la ciudad de Pilar, se desarrolló una Gran Asamblea Popular con el objetivo de fundar la Universidad de Pilar en Formación. Su sede fue la ciudad de Pilar, capital del Departamento de Ñeembucú y de esta forma, la institución iniciaba sus actividades, con el apoyo del sector privado. Fueron partícipes de esta asamblea autoridades nacionales y representantes de la educación superior de la República Argentina. En diciembre de 1994, por ley 529/94 crea oficialmente la Universidad Nacional de Pilar (Facultad de Ciencias Contables, Administrativas y Económicas UNP, 2015).

El Consejo de Universidades, por Resolución $N^{\circ} 6$ del año 1994, otorgó el parecer favorable para la creación y funcionamiento de la Universidad Nacional de Pilar y en el documento se observan los grados académicos y títulos profesionales que se otorgarán inicialmente, entre ellos, el de Licenciado en Contabilidad y Administración Rural. En el año 1995, por Resolución 80 del Consejo Superior, se creó la Facultad de Ciencias Contables, Administrativas y Económicas y la oferta educativa pasa a denominarse Licenciatura en Ciencias Contables.

La formación profesional, a nivel de grado, de la carrera de Contaduría Pública Nacional en la Universidad Nacional de Pilar, inicia con la Licenciatura en Ciencias Contables, 
creada en virtud a resoluciones del Consejo Directivo de la Facultad de Ciencias Contables, Administrativas y Económicas, la que fue homologada por el Consejo Superior Universitario de la Universidad Nacional de Pilar, en el año 1997 (Facultad de Ciencias Contables, Administrativas y Económicas - UNP, 1997), (Universidad Nacional de Pilar., 1997).

En el año 2000, fruto de una actualización curricular, nace la carrera de Auditoría y Contaduría Pública Nacional, que tuvo aprobación por los organismos de la Universidad Nacional de Pilar, y por el Consejo de Universidades (Facultad de Ciencias Contables, Administrativas y Económicas - UNP, 2000), (Universidad Nacional de Pilar, 2000), (Consejo de Universidades, 2001).

La carrera Contaduría Pública Nacional, creada en el año 2009, por el Consejo Superior Universitario de la Universidad Nacional de Pilar fue objeto de actualizaciones varias. En el año 2017, su última actualización, fue aprobada por el Consejo Nacional de Educación Superior y acreditada por la Agencia Nacional de Evaluación y Acreditación de la Educación Superior (Facultad de Ciencias Contables, Administrativas y Económicas UNP, 2016) (Universidad Nacional de Pilar, 2016), (Consejo Nacional de Educación Superior, 2017), (Agencia Nacional de Evaluación y Acreditación de la Educación Superior - ANEAES, 2018).

En el cuadro siguiente se describen los antecedentes de la carrera Contaduría Pública Nacional de la Universidad Nacional de Pilar.

\begin{tabular}{|c|c|c|c|}
\hline $\begin{array}{l}\text { Denominación } \\
\text { de la carrera }\end{array}$ & Resolución Consejo Directivo & $\begin{array}{c}\text { Resolución Consejo Superior } \\
\text { Universitario }\end{array}$ & $\begin{array}{c}\text { Aprobación del Consejo } \\
\text { de Universidades / } \\
\text { CONES }\end{array}$ \\
\hline $\begin{array}{c}\text { Contabilidad y } \\
\text { Administración } \\
\text { Rural } \\
\end{array}$ & & & $\begin{array}{c}\text { Resolución } \\
\mathrm{N}^{\circ} 6 / 94 \\
\end{array}$ \\
\hline $\begin{array}{l}\text { Licenciatura } \\
\text { en Ciencias } \\
\text { Contables }\end{array}$ & $\begin{array}{c}\text { No 36/97 "Por la cual se aprueba el } \\
\text { nuevo proyecto Plan Curricular } \\
\text { 1998/2000 de la Facultad de } \\
\text { Ciencias Contables, } \\
\text { Administrativas y Económicas de la } \\
\text { Universidad Nacional de Pilar" }\end{array}$ & $\begin{array}{c}\mathbf{N}^{\circ} \mathbf{6 6 / 9 7} \text { "Por la cual se } \\
\text { aprueba el nuevo plan curricular } \\
\text { de la Facultad de Ciencias } \\
\text { Contables, Administrativas y } \\
\text { Económicas de la UNP. }\end{array}$ & \\
\hline $\begin{array}{c}\text { Auditoría y } \\
\text { Contaduría } \\
\text { Pública } \\
\text { Nacional }\end{array}$ & $\begin{array}{c}\mathbf{N}^{\circ} \mathbf{7 5 / 2 0 0 0} \text { "Por la cual se aprueba } \\
\text { el Plan Curricular de la nueva } \\
\text { carrera de Auditoría y Contaduría } \\
\text { Pública en la Facultad de Ciencias } \\
\text { Contables, Administrativas y } \\
\text { Económicas de la Universidad } \\
\text { Nacional de Pilar" }\end{array}$ & $\begin{array}{l}\mathbf{N}^{\circ} \mathbf{2 5 / 2 0 0 0} \text { "Por la cual se } \\
\text { solicita al Consejo de } \\
\text { Universidades la Habilitación de } \\
\text { las Facultades y de las carreras } \\
\text { implementadas en la UNP por } \\
\text { Resoluciones del Consejo } \\
\text { Superior Universitario. }\end{array}$ & $\begin{array}{c}\text { Acta 86/2001 - Aprueba } \\
\text { la habilitación de la } \\
\text { carrera. }\end{array}$ \\
\hline
\end{tabular}




\begin{tabular}{|c|c|c|c|}
\hline & & $\begin{array}{c}\text { En su Art. } 4^{\circ} \text { Aprueba el Plan } \\
\text { Curricular de la Carrera } \\
\text { Auditoría y Contaduría Pública. } \\
\text { Art. } 5^{\circ} \text { Autoriza la } \\
\text { implementación de la carrera } \\
\text { ACPN previa habilitación por el } \\
\text { Consejo de Universidades. }\end{array}$ & \\
\hline \multirow[t]{2}{*}{$\begin{array}{c}\text { Contaduría } \\
\text { Pública } \\
\text { Nacional }\end{array}$} & $\begin{array}{c}\mathbf{N}^{\circ} \mathbf{2 7 6 / 2 0 0 9} \text { "Por la cual se } \\
\text { aprueba la Renovación Curricular } \\
\text { de las carreras de Contaduría } \\
\text { Pública Nacional y Administración } \\
\text { de Empresas y se implementa a } \\
\text { partir del año académico } 2010 \text { en la } \\
\text { Facultad de Ciencias Contables, } \\
\text { Administrativas y Económicas de la } \\
\text { Universidad Nacional de Pilar" }\end{array}$ & $\begin{array}{l}\mathbf{N}^{\circ} \mathbf{1 1 4 / 2 0 0 9} \text { "Por la cual se } \\
\text { aprueban las actualizaciones de } \\
\text { los planes curriculares de las } \\
\text { carreras "Auditoría y } \\
\text { Contaduría Pública Nacional" y } \\
\text { "Licenciatura en Ciencias } \\
\text { Administrativas" y se habilitan } \\
\text { las carreras de grado } \\
\text { "Contaduría Pública Nacional" } \\
\text { y "Licenciatura en } \\
\text { Administración de Empresas" } \\
\text { en la Facultad de Ciencias } \\
\text { Contables, Administrativas y } \\
\text { Económicas de la UNP" }\end{array}$ & \\
\hline & $\begin{array}{c}\mathbf{N}^{\circ} \mathbf{4 5 4 / 2 0 1 6} \text { "Por la cual se } \\
\text { aprueba la actualización del } \\
\text { Proyecto Educativo de la carrera } \\
\text { Contaduría Pública Nacional y de la } \\
\text { carrera Adm. de Emp. en la Fac. de } \\
\text { C. Contables, Adm. y Ec. de la } \\
\text { UNP }\end{array}$ & $\begin{array}{c}\mathbf{N}^{\circ} \mathbf{1 3 1 / 2 0 1 6} \text { “Por la cual se } \\
\text { homologa la Resolución } N^{\circ} \\
\text { 454/2016 del Consejo Directivo } \\
\text { de la Facultad de Ciencias } \\
\text { Contables, Administrativas y } \\
\text { Económicas. }\end{array}$ & $\begin{array}{l}\text { Resolución } \mathbf{N}^{\circ} \mathbf{4 1 1 / 2 0 1 7} \\
\text { Acreditada según } \\
\text { Resolución } 208 \text { de } \\
\text { ANEAES. }\end{array}$ \\
\hline
\end{tabular}

\section{Fuente: Elaboración propia.}

La carrera de grado Contaduría Pública Nacional, contempla en su proyecto educativo los saberes, habilidades, competencias y actitudes para la formación profesional competitiva. Atiende a las demandas cualitativas del mercado laboral, pertinentes con el desarrollo nacional y regional. Los planes y programas, tendientes a construir y consolidar la comunidad académica, están basados en el proyecto académico de la carrera y, el mismo está orientado a que los alumnos adquieran una formación sólida como persona y profesional, pues sustenta su modelo educativo en el Enfoque Cognitivo y de Realización Personal. La comunidad académica está constituida por los estamentos de directivos, docentes, estudiantes, funcionarios administrativos y de apoyo, y egresados, que sustentan a la institución (Universidad Nacional de Pilar, 2016).

La Universidad Nacional de Pilar, por ser de gestión oficial, cuenta con financiamiento del Presupuesto General de la Nación, por ende, la carrera también se encuentra financiada con esos recursos. Los estudiantes provienen de distintos distritos del departamento de Neembucú y de la ciudad de Pilar. En relación al nivel económico y 
social de los alumnos que acuden a la institución en su mayoría son de nivel medio y bajo, atendiendo a la solicitud de becas presentadas por los alumnos; las que son aprobadas conforme a la disponibilidad presupuestaria. El nivel intelectual se determina a través de los certificados de estudios que presentan los alumnos y del informe de evaluación. La población de los alumnos se distribuye en la franja etaria de 18 a 25 años. (Informe Institucional, 2017)

\section{REFERENCIAS}

Agencia Nacional de Evaluación y Acreditación de la Educación Superior - ANEAES. (2018, 18, julio). Por la cual se dispone la acreditación de la carrera Contaduría Pública, sede Pilar, dependiente de la Facultad de Ciencias Contables, Administrativas y Económicas de la Universidad Nacional de Pilar.

Arévalo Galindo, N. E. (2015). Huellas de la Educación Contable, a inicios del siglo XX. Saber, Ciencia y Libertad, 195 - 202.

Cano, A., Restrepo, C., \& Villa, O. (2017). Aportes de Fray Luca Pacioli al desarrollo de la contabilidad: Origen y difusión de la partida doble. Espacios, 1-11.

Carrizo, W. (2015). Contabilidad y Profesión: La evolución de la profesión de Contador público y de las instituciones de enseñanza de la Contabilidad en la República Argentina (1974-1960). Particularidades de la región patagónica. De Computis, Revista Española de historia de la Contabilidad, 6 - 29.

Casal, R., \& Viloria, N. (2007). La Ciencia Contable.Su historia, filosofía, evolución y su producto. Actualidad Contable Faces, 19-28.

Colegio de Contadores del Paraguay. (2016). 100 años. Asunción.

Congreso de la Nación Paraguaya. (1992, 9, enero). Ley 125 Que establece el nuevo Régimen Paraguayo.

Congreso de la Nación Paraguaya. (2004, 5, julio). Ley $N^{\circ} 2124$ De reordenamiento administrativo y de adecuación fiscal.

Congreso de la Nación Paraguaya. (2019, 25, setiembre). Ley $N^{\circ} 6380$ De modernización y simplificación del sistema tributario nacional .

Consejo de Universidades. (1994). Resolución $N^{\circ}$ 06/94 Que crea la Universidad Nacional de Pilar. Asunción.

Consejo de Universidades. (2001, 31, octubre). Acta $N^{\circ} 86$. 
Consejo Nacional de Educación Superior. (2017, 18, agosto). Resolución 411 Por la cual se aprueba la actualización de la carrera Contaduría Pública Nacional de la Universidad Nacional de Pilar - Sede Central/Pilar.

Corte Suprema de Justicia . (18 de abril de 2019). Corte Suprema de Justicia . Obtenido de Corte Suprema de Justicia : https://www.csj.gov.py/legislacion

Facultad de Ciencias Contables, Administrativas y Económicas - UNP. (1997, 24, junio). Resolución $N^{\circ} 36 / 97$ Por la cual se aprueba el nuevo proyecto Plan Curricular 1998/2000 de la Facultad de Ciencias Contables, Administrativas y Económicas de la Universidad Nacional de Pilar. Pilar.

Facultad de Ciencias Contables, Administrativas y Económicas - UNP. (2000, 9, agosto). Resolución $N^{\circ}$ 75/2000 Por la cual se aprueba el Plan Curricular de la nueva carrera de Auditoría y Contaduría Pública en la Facultad de Ciencias Contables, Administrativas y Económicas de la Universidad Nacional de Pilar.

Facultad de Ciencias Contables, Administrativas y Económicas - UNP. (2009, 02, diciembre). Resolución 276/2009 Aprueba la renovación curricular de las carreras de Contaduría Pública Nacional y Administración de Empresas y se implementa a partir del año académico 2010 en la Facultad de Ciencias Contables, Administrativas y Económicas de la UNP.

Facultad de Ciencias Contables, Administrativas y Económicas - UNP. (2016, 21, noviembre). Resolución $N^{\circ}$ 454/2016 Que aprueba la actualización curricular de las carreras Contaduría Pública Nacional y Licenciatura en Administración de Empresas.

Facultad de Ciencias Contables, Administrativas y Económicas UNP. (2015). Informe Institucional.

Facultad de Ciencias Económicas - Universidad Nacional de Asunción. (8 de mayo de 2019). Facultad de Ciencias Económicas . Obtenido de https://www.eco.una.py/index.php/historia

Iriarte, R. A. (2011). La Educación Técnica y Profesional de Nivel. La Educación Técnica $y, 35$.

Mileti, M., Berri, A. M., Gastaldi, J., Ilundain, L., Judais, A., Marcolini, S., \& Verón, C. (2001). Evolución Histórica de la Contabilidad y su relación con la Investigación y regulación contable en Estados Unidos, Sur de Europa y Argentina. Sextas Jornadas 
"Investigaciones en la Facultad" de Ciencias Económicas y Estadística, noviembre de 2001.

Ministerio de Educación y Ciencias . (15 de abril de 2019). Ministerio de Educación y Ciencias. Obtenido de https://mec.gov.py/cmsmec/wpcontent/uploads/2010/02/breve-evolucion-historia-del-sistema-educativoparaguayo.pdf

Moran Alvarez, F. (2007). Historia de la Contabilidad - Los estudios mercantiles y las escuelas de comercio. España: Caja España.

Organización de los Estados Interamericanos para la Educación, 1. C. (s.f.). Sistemas Educativos Nacionales - Paraguay. Sistemas Educativos Nacionales - Paraguay Capítulo 9. Organización de los Estados Interamericanos para la Educación, la Ciencia y la Cultura (OEI).

Poder Legislativo. (1930). Ley 1135/30 Que reglamenta el ejercicio de la profesión de peritos mercantiles o contadores públicos.

Quinche Martín, F. L. (2006). Historia de la Contabilidad: Una revisión de las Perspectivas Tradicionales y. Revista de la Facultad de Ciencias Económicas Universidad Nacional de Colombia, 187-202.

Rivero Brest, I. S. (2012). Pilar, la heróica. Pilar: El lector.

Rojas Cuenca, F. (2010). Tesis de Maestría. Evolución de la Educación Paraguaya. Universidad Tecnológica Intercontinental, Asunción.

Universidad Nacional de Pilar . (1995). Resolución 80/95 Por la cual se crean las Facultades de la Universidad Nacional de Pilar. Pilar.

Universidad Nacional de Pilar. (2000, 4, noviembre). Resolución $N^{\circ}$ 25/2000 Por la cual se solicita al Consejo de Universidades la Habilitación de las Facultades y de las carreras implementadas en la UNP por Resoluciones del Consejo Superior Universitario.

Universidad Nacional de Pilar. (2009, 4, diciembre). Resolución $N^{\circ}$ 114/2009 Aprueba actualizaciones de planes de las carreras Auditoría y Contaduría Pública Nacional y Licenciatura en Ciencias Administrativas y se habilitan las carreras de grado Contaduría Pública Nacional y Administración de Empresas.

Universidad Nacional de Pilar. (2016). Proyecto Educativo Carrera Contaduría Pública Nacional. Pilar. 
Universidad Nacional de Pilar. (2016, 21, noviembre). Resolución $N^{\circ}$ 131/2016 Que homologa la Resolución $N^{\circ}$ 454/2016 del Consejo Directivo de la Facultad de Ciencias Contables, Administrativas y Económicas.

Universidad Nacional de Pilar. (1997, 10, diciembre). Resolución $N^{\circ}$ 66/97 Por la cual se aprueba el nuevo plan curricular de la Facultad de Ciencias Contables, Administrativas y Económicas de la UNP. 